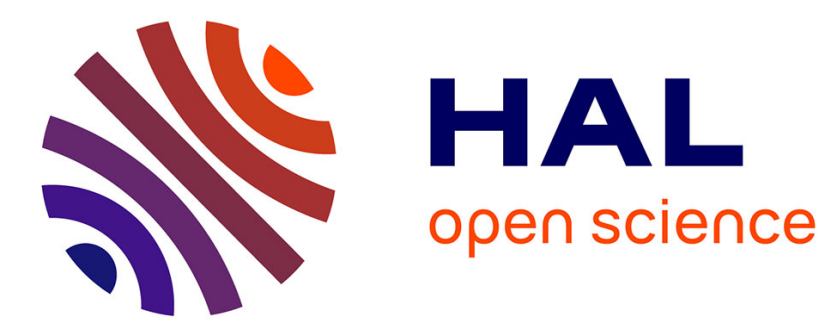

\title{
Loudness of low-frequency pure tones lateralized by interaural time differences
}

Vincent Koehl, Mathieu Paquier

\section{To cite this version:}

Vincent Koehl, Mathieu Paquier. Loudness of low-frequency pure tones lateralized by interaural time differences. Journal of the Acoustical Society of America, 2015, 137 (2), pp.1040-1043. 10.1121/1.4906262 . hal-01115878

\section{HAL Id: hal-01115878 \\ https://hal.science/hal-01115878}

Submitted on 23 Feb 2015

HAL is a multi-disciplinary open access archive for the deposit and dissemination of scientific research documents, whether they are published or not. The documents may come from teaching and research institutions in France or abroad, or from public or private research centers.
L'archive ouverte pluridisciplinaire HAL, est destinée au dépôt et à la diffusion de documents scientifiques de niveau recherche, publiés ou non, émanant des établissements d'enseignement et de recherche français ou étrangers, des laboratoires publics ou privés. 


\title{
Loudness of low-frequency pure tones lateralized by interaural time differences
}

January 3, 2015

\author{
Vincent Koehl ${ }^{\mathrm{a})}$ and Mathieu Paquier \\ University of Brest, CNRS, Lab-STICC UMR 6285 \\ 6 avenue Victor Le Gorgeu - CS 93837 \\ 29238 Brest Cedex 3, France
}

a) e-mail: vincent.koehl@univ-brest.fr 


\begin{abstract}
Directional loudness is that phenomenon by which the loudness of a sound may vary according to the localization of its source. This phenomenon has been mainly observed for high-frequency sounds, for sources located in the horizontal plane. Because of the acoustic shadow of the head, the left and right ear pressures are modified depending on the source azimuth and the global loudness resulting from a summation process may vary accordingly. Directional loudness has also been reported to occur at $400 \mathrm{~Hz}$, where shadowing effects are usually rather small. It might therefore be suspected that directional loudness effects could be influenced by other parameters involved in the localization process. This study assessed the loudness of low-frequency pure tones (200 and $400 \mathrm{~Hz}$ ) lateralized with headphones by applying an interaural time difference (ITD) but no interaural level difference. It showed small but significant variations of loudness with respect to ITD at a low loudness level (40 phon): ITD values associated with virtual azimuths of $\pm 60^{\circ}$ and $\pm 90^{\circ}$ led to a small but significant increase in loudness (up to $1.25 \mathrm{~dB}$ ). However, there was no such effect at a moderate loudness level (70 phon).
\end{abstract}

Pacs numbers: 43.66.Cb, 43.66.Pn, 43.66.Rq 
Koehl and Paquier, Directional loudness of low-frequency tones, p. 3

\section{INTRODUCTION}

The loudness of a sound may vary according to the location of the source. Such a phenomenon has been highlighted by presenting bands of noise through loudspeakers located at various directions around a listener in an anechoic room (Robinson and Whittle, 1960; Sivonen and Ellermeier, 2006). As an example, a third-octave noise band centered at $5 \mathrm{kHz}$ emitted by a lateral source $\left( \pm 90^{\circ}\right)$ would be perceived as louder than the same sound emitted by a frontal source $\left(0^{\circ}\right)$. This effect, known as directional loudness, is largely accounted for by physical modifications of the stimulation. The sound pressure at each of the two ears is affected to a different extent depending on the source azimuth and the loudness that results from a binaural summation process (Sivonen and Ellermeier, 2011) is affected as well. Consequently, this effect has been mainly observed for high-frequency sounds, for which at-ear pressures are modified because of the perturbation of the sound field by the head. The resulting interaural level differences (ILD) are used for high-frequency localization, above about $1500 \mathrm{~Hz}$ (Moore, 2012). Directional effects are implicitly already taken into account in the current standard for loudness calculation (ANSI S3.4, 2012) as the inputs to this model are at-ear measurements (i.e. left and right pressures that may differ according to the localization of the source). However, a more explicit consideration of directional effects, based on binaural loudness modeling, was recently proposed by Sivonen and Ellermeier (2006) and such considerations were also 
Koehl and Paquier, Directional loudness of low-frequency tones, p. 4

taken into account in a model proposed by Moore and Glasberg (2007).

When presenting third-octave noise bands through loudspeakers positioned $2 \mathrm{~m}$ from the listener's head in the horizontal plane, Sivonen and Ellermeier (2006) observed directional effects on overall loudness at $400 \mathrm{~Hz}$. There is little acoustic shadow of the head below $500 \mathrm{~Hz}$ (Moore, 2012), so the ILD is small for a distant source. Nevertheless, ILDs vary markedly from one subject to another (even below $500 \mathrm{~Hz}$ ) and from one study to another, depending on the measurement method (Shaw, 1974). Sivonen and Ellermeier (2006) reported that the differences in sound pressure levels they measured at the two ears were not negligible and could reach up to $5 \mathrm{~dB}$ at $400 \mathrm{~Hz}$ for an azimuth of $\pm 90^{\circ}$. However, Sivonen and Ellermeier also observed that, for one subject among eight, the directional loudness sensitivity (DLS) at $400 \mathrm{~Hz}$ was higher than what would be expected from the related pressure measurements (at 45 and $65 \mathrm{~dB}$ SPL). In addition, the data of Sivonen and Ellermeier were used by Moore and Glasberg (2007) as input to their loudness model. They reported a tendency for the measured DLS values to be slightly higher than the predicted values at $5000 \mathrm{~Hz}$. Therefore, regardless of whether or not the left and right ear pressures are equal, it may be suspected that directional loudness effects are not caused only by pressure modifications. These effects might also depend on the absolute level. Such a dependence was reported by Sivonen and Ellermeier $(2006,2011)$ when comparing the levels required to achieve equal loudness in monaural and binaural listening situations. The 
Koehl and Paquier, Directional loudness of low-frequency tones, p. 5

level of a monaural stimulus needs to be increased by $3 \mathrm{~dB}$ near threshold but by $6-10 \mathrm{~dB}$ at high levels to be matched in loudness with its binaural equivalent. However, Epstein and Florentine (2012) argue that such differences are only due to the fact that monaural stimuli are not ecologically valid. They showed that increasing the ecological validity of monaural listening by providing visual cues significantly reduced these differences.

For a source placed off-axis in the horizontal plane, the left and the right ear signals differ also in their phases or arrival times, and those differences can be used as a low-frequency localization cue. According to Moore (2012), this localization cue can be equivalently described as interaural time or phase difference for pure tones. Below $1500 \mathrm{~Hz}$, sine tones are well lateralized on the basis of ITD (Zhang and Hartmann, 2006). A few studies have investigated the influence of interaural time/phase differences on binaural loudness summation. In one of their experiments, Mulligan et al. (1985) showed, by matching the loudness of phase-shifted pure tones with that of a binaural reference tone (phase angle of $0^{\circ}$ ) at $74.5 \mathrm{~dB}$ SPL, a stepwise dependence of loudness of binaural pure tones on interaural phase. A difference of $2.4 \mathrm{~dB}$ in the level required for equal loudness was observed when the interaural phase of $250-\mathrm{Hz}$ pure tones reached $\pm 59^{\circ}$, corresponding to an interaural time difference of $\pm 650 \mu \mathrm{s}$, which is the largest value that can be obtained from Woodworth's spherical head model (1938). Surprisingly, an increase of $+2.4 \mathrm{~dB}$ occured if the interaural phase led to the left $\left(-59^{\circ}\right)$ while a decrease of $-2.4 \mathrm{~dB}$ occured 
Koehl and Paquier, Directional loudness of low-frequency tones, p. 6

for the opposite side $\left(+59^{\circ}\right)$. However, this was observed using three listeners only. Algom et al. (1988) studied the relations between loudness and lateralization for binaural stimuli at suprathreshold levels $(20,40,43,46$ and $49 \mathrm{~dB}$ SL). Clicks were lateralized by introducing time differences and seven subjects were asked to estimate both the loudness and the lateralization. The results showed that the magnitude estimates continuously decreased as time differences increased. In this case, loudness appeared to decrease with lateralization whatever the side. Stimuli were presented via headphones in these two studies, and the results were not fully consistent with those obtained with loudspeakers (increase of loudness with lateralization whatever the side). Such discrepancies may be due to the relative small numbers of subjects, to the fact that headphone-presented stimuli may appear to come from inside the head and that signals with high-frequency content such as clicks would usually lead to an ILD (Moore, 2012).

This study investigated the possible effects of interaural time differences (ITDs) on the perception of the loudness of low-frequency pure tones (200 and $400 \mathrm{~Hz}$ ) presented via headphones. The same sound-pressure level was produced at the two ears and the stimuli were lateralized by introducing interaural time differences only. The effect of ITD on loudness was investigated at two absolute levels (40 and 70 phon) as DLS may be level dependent.

\section{EXPERIMENTAL SETUP}


Koehl and Paquier, Directional loudness of low-frequency tones, p. 7

The effect of ITD on loudness was investigated by matching lateralized pure tones with a diotic reference of the same frequency.

\section{A. Stimuli}

Two frequencies were used: $400 \mathrm{~Hz}$ (where directional effects were observed by Sivonen and Ellermeier, 2006) and $200 \mathrm{~Hz}$ (where presenting the same pressure at the two ears should appear more natural to the listener, acccording to Feddersen et al., 1957).

The ITD value related to a virtual incidence angle $\theta_{i n c}$ for a sound source in the horizontal plane was derived from Kuhn's low-frequency model (1977), which is valid below $500 \mathrm{~Hz}:$

$$
\mathrm{ITD}=\frac{3 a}{c_{0}} \sin \theta_{i n c}
$$

where $a=8.75 \mathrm{~cm}$ is the average head radius and $c_{0}=340 \mathrm{~m} \cdot \mathrm{s}^{-1}$ is the speed of sound in the air. An ITD value obtained this way was introduced between the left and right channels of an initially diotic pure tone (that should be perceived as centered) to lateralize it. Seven virtual incidence angles $\left(0^{\circ}, \pm 30^{\circ}, \pm 60^{\circ}\right.$ and $\left.\pm 90^{\circ}\right)$ were selected to study possible asymmetric effects (Mulligan et al., 1985). Corresponding ITD values (respectively $\pm 386 \mu \mathrm{s}, \pm 669 \mu \mathrm{s}$ and $\pm 772 \mu \mathrm{s})$ were higher than the interaural time/phase difference thresholds at these frequencies and should enable the lateralization of pure tones, according to Zhang and Hartmann (2006). A negative ITD means that the stimulus led on the left.

Stimuli were to be matched to diotic references whose level was fixed at either 40 or 
Koehl and Paquier, Directional loudness of low-frequency tones, p. 8

Table 1: Sound pressure levels of the reference stimuli.

\begin{tabular}{ccc}
\hline \hline$f(\mathrm{~Hz})$ & $N($ phon $)$ & $L(\mathrm{~dB}$ SPL $)$ \\
\hline 200 & 40 & 53.4 \\
400 & 40 & 45.0 \\
200 & 70 & 77.9 \\
400 & 70 & 72.6 \\
\hline \hline
\end{tabular}

70 phon by placing the test headphones (Sennheiser HD650, circumaural, open) on a dummy head (Neumann KU100) and by adjusting the sound pressure levels (see Table 1) on each ear according to the ISO 226 standard (2003). The duration of each stimulus was $1.6 \mathrm{~s}$. Its onset and offset were smoothed by 100-ms-long raised-cosine functions.

\section{B. Procedure}

The loudness matching task was based on a two-interval, adaptive forced-choice procedure converging on the point of subjective equality (PSE) by following a 1-up-1-down rule (Levitt, 1971). This $2 \mathrm{AFC}$ procedure was very similar to the one used by Sivonen and Ellermeier (2006). In each trial, a test sound (directional stimulus of variable level) and a reference sound (diotic stimulus) lasting $1.6 \mathrm{~s}$ each were consecutively presented in random order with a 500-ms pause in between. The task was to indicate whether the first or the second sound was perceived as louder, regardless of any other difference. The instructions were given both orally and in written form. The subject responded by clicking a button on a MATLAB graphical user interface. The sound-pressure level of the test sound was 
Koehl and Paquier, Directional loudness of low-frequency tones, p. 9

lowered by a given amount when the subject judged it to be louder, whereas it was increased by the same amount when the subject judged the reference to be louder. The step size was initially set to $4 \mathrm{~dB}$ and was decreased to $1 \mathrm{~dB}$ after two reversals (a reversal denotes a change in direction in the matching sequence). The starting level of each stimulus was randomly set $10 \mathrm{~dB}$ above or below the level of the diotic reference (Table 1), thus providing a clearly noticeable loudness differences at the start of the matching process. A total of eight reversals was collected and the arithmetic mean of the levels at the last six of them was used to derive the PSE.

The two loudness level reference values (40 and 70 phon) were used in two different sessions that were presented in random order. In each session, the 14 adaptive sequences related to the experimental conditions (2 frequencies, 7 ITDs) were randomly reordered and interleaved on a trial-by-trial basis, providing some random sampling of ITD values, frequencies and starting levels. From the subject's point of view, each session appeared as a succession of unrelated paired comparisons of loudness. The subject sat in an audiometric booth and was asked to place the test headphones comfortably over his (or her) ears and to not modify this position once the test had started. The first session was preceded by a 3-min pretest to familiarize the subject with the task and the response interface. At the end of the first session, the subject was offered a 5-min break, during which (s)he was asked again to not remove the headphones. The second session could be 
Koehl and Paquier, Directional loudness of low-frequency tones, p. 10

started upon request, by clicking a button on the graphical interface. A test (i.e. 2 sessions including pretest and break) lasted approximately $1 \mathrm{~h}$ and was conducted twice, on two different days, for each subject to assess test-retest variability.

Eleven (2 women and 9 men) sound engineering students (Bachelor's degree) from the University of Brest took part and were remunerated for their participation. They had normal hearing thresholds $(\leq 10 \mathrm{~dB} H \mathrm{HL})$ based on an audiogram taken in the month preceding this test. None of them had experience in laboratory listening tests.

\section{Results}

The PSE is presented as the difference between the matched level and the reference level. The PSEs obtained in each session (40 or 70 phon) were analyzed using repeated-measures analysis of variance with test repetition (2 levels), frequency (2 levels) and ITD (7 levels) as within-subjects factors.

For the 40-phon stimuli, only the effect of ITD was significant $(F(6,60)=9.398$; $p<0.001)$. Fig. 1 shows that the PSE tended to decrease with increasing absolute value of the ITD. According to Fisher's LSD test, the stimuli with ITDs of $\pm 772 \mu$ s were matched at a significantly different value $(p<0.001$ in both cases) than the diotic one. The stimuli with ITDs of $\pm 669 \mu$ s were also matched at a significantly different value $(p<0.05$ in both cases) than the diotic one. However, the difference of approximately $0.6 \mathrm{~dB}$ was of the same order as the intensity differential threshold for such stimuli (Fletcher, 1953). The 
Koehl and Paquier, Directional loudness of low-frequency tones, p. 11

difference was approximately $1.25 \mathrm{~dB}$ when the interaural time difference was $\pm 772 \mu \mathrm{s}$.

The PSE being negative, it can be inferred that these stimuli would have been perceived as louder than the reference if presented at the same physical level.

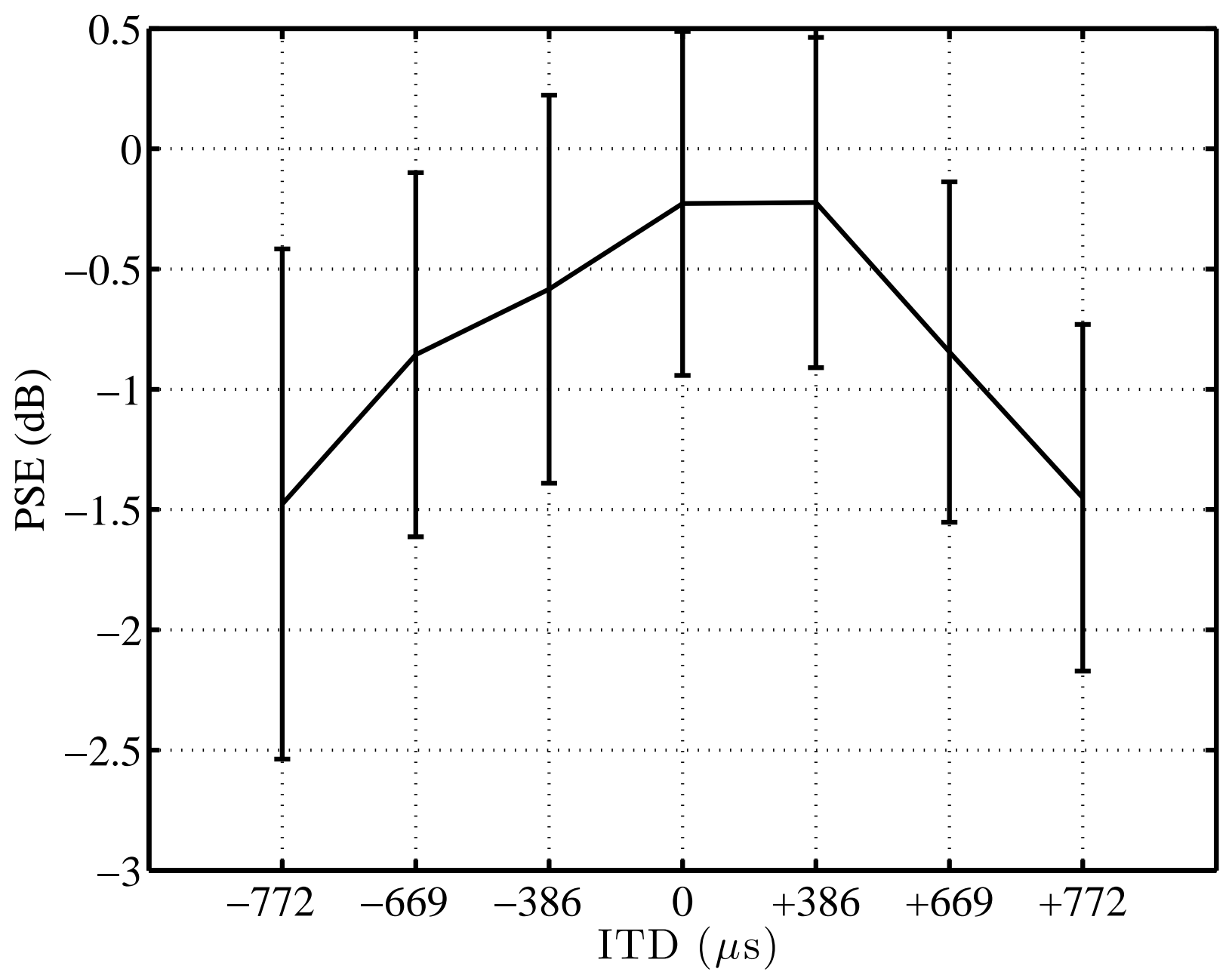

Figure 1: Mean PSE as a function of ITD at 40 phon, with $95 \%$ confidence intervals.

No significant effect $(F(6,60)=2.218 ; p=0.053)$ or interaction involving ITD was 
Koehl and Paquier, Directional loudness of low-frequency tones, p. 12

found at 70 phon. Frequency had a significant effect $(F(1,10)=7.941 ; p<0.05)$. The $200-\mathrm{Hz}$ stimuli were matched at a statistically higher value than the $400-\mathrm{Hz}$ ones. However, the mean difference was only $0.2 \mathrm{~dB}$.

\section{DISCUSSION}

ITDs resulted in an increase of loudness for low-frequency pure tones at a low level (40 phon). The effect depicted in Fig. 1 indicates a symmetric increase of loudness with increasing lateralization, in contrast to the observations of Mulligan et al. (1985) and Algom et al. (1988) who respectively observed an asymmetric effect and a decrease of loudness with phase/time-induced lateralization. However, these observations were based on a very small number of subjects for Mulligan et al. (1985) and on signals that should also have had ILDs for Algom et al. (1988). The results of the present study are in agreement with previous studies of directional loudness for real sources (Robinson and Whittle, 1960; Sivonen and Ellermeier, 2006). These studies showed that loudness increased with increasing absolute source azimuth. However, such an effect was observed by Sivonen and Ellermeier (2006) at 45 and 65 dB SPL for third-octave noise bands, whereas here it was not significant at 70 phon (77.9 or $72.6 \mathrm{~dB}$ SPL as indicated in Table 1) for pure tones. The significant effect observed at 40 phon supports the assumption that directional loudness sensitivity is not determined by at-ear pressures only, but that other parameters related to source localization (ITD in the present case) may affect the process. 
Koehl and Paquier, Directional loudness of low-frequency tones, p. 13

The effect of ITD on loudness at 40 phon is comparable to the effect of interaural correlation on loudness reported by Edmonds and Culling (2009), although this was observed at a higher level (70 dB SPL) for 1-ERB wide noisebands. Using a loudness-matching paradigm, they showed that the level of noises with an interaural correlation of 0 had to be $2 \mathrm{~dB}$ less than the level of noises with interaural correlations of \pm 1 to achieve equal loudness. According to them, such results are consistent with expectations based on theories of binaural unmasking, as uncorrelated signals might be better separated from background noise and be perceived as louder. Assuming this hypothesis holds for internal noise that is partially correlated (Yost, 1988), our results are consistent with the observations of Zwicker and Henning (1991) on the effect of interaural phase on loudness for $250-\mathrm{Hz}$ tones presented with a masking noise that was in phase at the two ears $\left(N_{0}\right)$. Interaurally out-of-phase signals $\left(N_{0} S_{\pi}\right.$ condition) were perceived as louder than in-phase signals ( $N_{0} S_{0}$ condition). Loudness increased with increasing interaural phase difference near the masked threshold and up to 30 to $40 \mathrm{~dB}$ above it. This was not the case for higher tone levels, as for the results found at 70 phon in the present study. ITD-based lateralization could help separate the signal from internal noise, which could explain why loudness was effected by interaural phase at a low loudness level (40 phon) but not at a moderate loudness level (70 phon).

The effect of ITD on loudness could also be caused by "high-level" processes, as the 
Koehl and Paquier, Directional loudness of low-frequency tones, p. 14

lateralization of the source might be taken into account in the loudness process. The loudness increase could be aimed at focusing the listener's attention on a source that is out of the field of vision. Zahorik and Wightman (2001) showed an infuence of perceived source distance on loudness. They hypothesized that the brain is able to take source position into account to achieve loudness constancy when distance is varied. Loudness constancy was also observed by Epstein and Florentine (2012) for monaural to binaural listening situations, but could only be achieved when increasing the ecological validity of the monaural listening by providing visual cues. The possible effect of lateralization on loudness might be largely dependent on the experimental conditions, if caused by similar high-level processes, which might explain the discrepancies between studies conducted using loudspeakers and headphones. The role of such processes is still not clear, but not taking them into account is pointed out by Moore and Glasberg (2007) as a limitation of current loudness models.

\section{CONCLUSIONS}

The results show that low-frequency pure tones lateralized by introducing ITDs were perceived as louder than their diotic references when presented at a low loudness level (40 phon) but not at a moderate loudness level (70 phon).

\section{ACKNOWLEDGMENTS}

The authors wish to thank the staff and students from the "Image \& Son" department 
Koehl and Paquier, Directional loudness of low-frequency tones, p. 15

of the University of Brest for participating in this experiment.

\section{REFERENCES}

Algom, D., Adam, R., and Cohen-Raz, L. (1988). "Binaural summation and lateralization of transients: A combined analysis", J. Acoust. Soc. Am. 84, 1302-1315.

ANSI S3.4 (2012). "Procedure for the computation of loudness of steady sounds", American National Standards Institute, New York City, NY, USA.

Edmonds, B.A. and Culling, J.F. (2009). "Interaural correlation and the binaural summation of loudness", J. Acoust. Soc. Am. 125, 3865-3870.

Epstein, M. and Florentine, M. (2012). "Binaural loudness summation for speech presented via earphones and loudspeaker with and without visual cues", J. Acoust. Soc. Am. 131, 1302-1315.

Feddersen, W. E., Sandel, T. T., Teas, D. C., and Jeffress, L. A. (1957). "Localization of high-frequency tones", J. Acoust. Soc. Am. 29, 988-991.

Fletcher, H. (1953). Speech and Hearing in Communication, chapter 9. Minimum perceptible changes in frequency and sound pressure level, 144-152, second edition (Van Nostrand, Princeton, NJ, USA). 
Koehl and Paquier, Directional loudness of low-frequency tones, p. 16

ISO 226 (2003). "Acoustics - Normal equal-loudness-level contours", International Organization for Standardization, Geneva, Switzerland.

Kuhn, G. F. (1977). "Model for the interaural time differences in the azimuthal plane", J. Acoust. Soc. Am. 62, 157-167.

Levitt, H. (1971). "Transformed up-down methods in psychoacoustics", J. Acoust. Soc. Am. 49, 467-477.

Moore, B. C. J. (2012). An Introduction to the Psychology of Hearing, chapter 7. Space perception, 245-250, sixth edition (Brill, Leiden, The Netherlands).

Moore, B. C. J. and Glasberg, B. R. (2007). "Modeling binaural loudness", J. Acoust. Soc. Am. 121, 1604-1612.

Mulligan, B. E., Goodman, L. S., Gleisner, D. P., and Faupel, M. L. (1985). "Steps in loudness summation", J. Acoust. Soc. Am. 77, 1141-1154.

Robinson, D. W. and Whittle, L. S. (1960). "The loudness of directional sound fields", Acustica 10, 74-80.

Shaw, E. A. G. (1974). "Transformation of sound pressure level from the free field to the eardrum in the horizontal plane", J. Acoust. Soc. Am. 56, 1848-1861. 
Koehl and Paquier, Directional loudness of low-frequency tones, p. 17

Sivonen, V. P. and Ellermeier, W. (2006). "Directional loudness in an anechoic sound field, head-related transfer functions, and binaural summation", J. Acoust. Soc. Am. 119, $2965-2980$.

Sivonen, V. P. and Ellermeier, W. (2011). "Binaural loudness", in Loudness, edited by M. Florentine, A. N. Popper, and R. R. Fay, chapter 7, 169-179 (Springer, New York City, NY, USA).

Woodworth, R. S. (1938). Experimental Psychology, chapter 20. Hearing, 522 (Holt, New York City, NY, USA).

Yost, W. A. (1988). "The masking-level difference and overall masker level: Restating the internal noise hypothesis", J. Acoust. Soc. Am. 83, 1517-1521.

Zahorik, P. and Wightman, F. L. (2001). "Loudness constancy with varying sound source distance", Nat. Neurosci. 4, 78-83.

Zhang, P. X. and Hartmann, W. M. (2006). "Lateralization of sine tones-interaural time vs phase", J. Acoust. Soc. Am. 120, 3471-3474.

Zwicker, E. and Henning, G. B. (1991). "On the effect of interaural phase differences on loudness", Hear. Res. 53, 141-152. 
Koehl and Paquier, Directional loudness of low-frequency tones, p. 18

\section{V. * List of Figures}

1 Mean PSE as a function of ITD at 40 phon, with $95 \%$ confidence intervals. . 11 